\title{
Effect of Korean Red Ginseng on Noise-Induced Hearing Loss
}

\author{
Original Investigation \\ ๑ Serpil Mungan Durankaya ${ }^{1,2}$, ๑ Yüksel Olgunn ${ }^{3}$ ๑ Safiye Aktaş4,

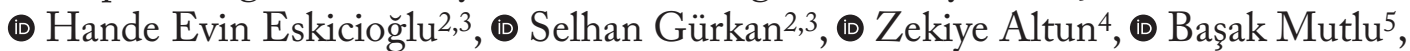 \\ ๑ Efsun Kolatan', ๑ Ersoy Doğan ${ }^{3}$, ๑ Osman Yılmaz ${ }^{6}$, ๑ Günay Kırkım²,3
}

${ }^{1}$ Department of Otorhinolaryngology, Audiology Programme, Institute of Health Sciences, Dokuz Eylül University, İzmir, Turkey

${ }^{2}$ Department of Audiometry, Vocational School of Health Services, Dokuz Eylül University, İzmir, Turkey

${ }^{3}$ Department of Otorhinolaryngology, School of Medicine, Dokuz Eylül University İzmir, Turkey

${ }^{4}$ Department of Basic Oncology, Institute of Oncology, Dokuz Eylül University, İzmir, Turkey

${ }^{5}$ Department of Audiology, School of Health Sciences, Medeniyet University, İstanbul, Turkey

${ }^{6}$ Department of Laboratory Animal Sciences, Dokuz Eylül University, İzmir, Turkey

\section{Abstract \\ ORCID ID of the authors: \\ S.M.D. 0000-0003-4236-434X; \\ Y.O. 0000-0003-1769-4224; \\ S.A. 0000-0002-7658-5565; \\ H.E.E. $0000-0001-6614-2341$ \\ S.G. 0000-0002-2872-5703; \\ Z.A. 0000-0002-1558-4534; \\ B.M. 0000-0002-9803-9258; \\ E.K. 0000-0003-4761-2779; \\ E.D. 0000-0003-0539-4232; \\ O.Y. 0000-0001-7512-5076 \\ G.K. 0000-0003-4170-5317. \\ Cite this article as: Mungan Durankaya S, Olgun Y, Aktas S, Eskicioğlu HE, Gürkan S, Altun Z, Mutlu B, Kolatan E, Doğan E, Yılmaz 0, Krikim G. Effect of Korean Red Ginseng on Noise-Induced Hearing Loss. Turk Arch Otorhinolaryngol 2021; 59(2): 111-7. \\ Corresponding Author: \\ Serpil Mungan Durankaya; serpil.mungan@deu.edu.tr \\ Received Date: 22.01.2021 \\ Accepted Date: 01.04 .2021 \\ Content of this journal is licensed under a Creative Commons Attribution 4.0 International License. Available online at www.turkarchotolaryngol.net \\ (c) (i) (5)}

DOI: 10.4274/tao.2021.2021-1-5
Objective: Noise-induced hearing loss (NIHL) is one of the most important problems affecting both social and professional life of patients. There is no treatment method considered to be successful on the hearing loss that has become a permanent nature. Aim of this study is to evaluate protective effect of Korean Red Ginseng (KRG) against NIHL in an animal model.

Methods: Twenty-eight rats were separated into four groups [control saline (group I), control KRG (group II), saline + noise (group III), KRG + noise (group IV)]. Rats in the saline and KRG groups were fed via oral gavage with a dose of $200 \mathrm{mg} / \mathrm{kg} /$ day throughout for 10 days. Fourteen rats (group III and IV) were exposed to $4 \mathrm{kHz}$ octave band noise at $120 \mathrm{~dB}$ SPL for 5 hours. Hearing levels of rats were evaluated by distortion product otoacoustic emissions (DPOAE) and auditory brainstem responses (ABR) at $4,8,12,16$ and $32 \mathrm{kHz}$ frequencies prior to and on days 1 , 7 and 10 after the noise exposure. Rats were sacrificed on 10th day, after the last audiological test. Cochlea and spiral ganglion tissues were evaluated by light microscopy.

Results: Audiological and histological results demonstrated that after noise the group IV showed better results than group III. In the noise exposed groups, the most prominent damage was seen at the $8 \mathrm{kHz}$ frequency region than other regions. After the noise exposure, DPOAE responses were lost in $1^{\text {st }}, 7^{\text {th }}$ and $10^{\text {th }}$ measurements in both group III and IV. Thus, we were not able to perform any statistical analyses for DPOAE results.

Conclusion: Our findings suggest that KRG seems to be an efficient agent against NIHL. There is need for additional research to find out about the mechanisms of KRG's protective effect.

Keywords: Noise, noise-induced hearing loss, antioxidants, treatment, ginseng, animal experimentation, audiology 


\section{Introduction}

Noise-induced hearing loss (NIHL) is one of the most important problems affecting both the social and the professional lives of patients (1-4). The mechanism of NIHL can be attributed to direct mechanical injury and indirect metabolic stress to the cochlea due to over production of free oxygen radicals $(1,2,3,5-9)$. Noise exposure damages different structural components in the inner ear such as hair cells, spiral ganglion, auditory nerve fibers $(3,5,7$, 9-11). These effects may evoke the formation of free oxygen radicals resulting in sensorineural hearing loss $(5,12)$. The risk of NIHL may be decreased by using hearing protection devices or by attenuating the environmental noise level. An alternative way to prevent or to cure NIHL may be the usage of antioxidants and pharmacological agents $(6,13)$.

Korean Red Ginseng (KRG) is used in traditional oriental cure with various beneficial effects for over 2,000 years (14-20). Saponin, also called ginsenoside, is a component of ginseng which is found to improve cardiac and immune functions (16-18). Cancer-protective, antihypertensive, anti-inflammatory, antidiabetic, antioxidant, anti-aging, and radiation protective properties of KRG have also been shown in recent studies $(14,16,21-23)$. Saponin may inhibit lipid peroxidation and demonstrates antioxidative effects by reducing free oxygen radicals which are known to play a key role in NIHL. The aim of this study is to evaluate possible protective effects of KRG against NIHL.

\section{Methods}

\section{Animals}

Twenty-eight male Wistar albino rats were used in this study. Wistar rats were obtained from the Dokuz Eylül University, Department of Laboratory Animal Science. They were weighing between 250-350 $\mathrm{g}$ and any rat showing a sign of ear infection was excluded. Experimental protocol was approved by the Ethics Committee of Animal Care and Use of the Dokuz Eylül University (protocol number: 46/2014). This study was performed in accordance with guidelines established by the Ethics Committee of Animal Care and Use of the University. During the study, all measures were taken to minimize the pain or the discomfort of the rats.

\section{Experimental Groups}

In this study we used four groups, each consisting of seven rats. Group I (control saline group) was given $200 \mathrm{mg} / \mathrm{kg} /$ day saline by gavage for 10 days. Group II (control KRG group) was given $200 \mathrm{mg} / \mathrm{kg}$ /day KRG by gavage for 10 days. The KRG extract (dissolved in distilled water) used in the research was provided.
On the first day of the study, the animals in group III (noise exposed saline group) and IV (noise exposed KRG group) were exposed to noise. Group III (noise exposed saline group) was given $200 \mathrm{mg} / \mathrm{kg} /$ day saline for 10 days by gavage one hour after noise exposure. Group IV (noise exposed KRG group) was given $200 \mathrm{mg} / \mathrm{kg} /$ day KRG for 10 days by gavage following one-hour noise exposure. The researchers who performed the audiological tests and the histological examinations were blinded to the groups. The control group animals were placed the same cage for the same duration as the noise trauma animals, but without noise exposure.

\section{Anaesthesia Procedure}

A combination of $40 \mathrm{mg} / \mathrm{kg}$ ketamine hydrochloride (Ketalar, Parke-Davis, USA) and $5 \mathrm{mg} / \mathrm{kg}$ xylazine hydrochloride (Rompun, Bayer, Germany) were used for anesthetizing the animals prior to audiological procedures.

\section{Noise Exposure}

Rats were exposed to one octave-band noise centered at 4 $\mathrm{kHz}$ at $120 \mathrm{~dB}$ sound pressure level (SPL) for five hours in a room. Speakers (Spekon CT-51AS, China) by a noise generator and power amplifier (Konig PRO-2008S, Louisiana, USA) were used to produce the noise. Sound level calibrations were tested at different points of the room to ensure the stability of the stimulus.

\section{Distortion Products Otoacoustic Emissions}

Distortion Products Otoacoustic Emissions (DPOAE) were performed with the Otodynamics Echoport ILO-V6 Cochlear Emission Analyzer 5.61 (Otodynamics, London, UK), using neonate probe. The f2/f1 ratio was kept at 1.22. The levels of the stimulus were L1 (65 dB SPL) for f1 and L2 (55 dB SPL) for $\mathrm{f} 2$ frequency. The baseline hearing condition of rats was measured with DPOAE, and the signal-to-noise ratio (SNR) was measured at seven frequencies between 1 to $8 \mathrm{kHz}$.

\section{Auditory Brainstem Responses}

Auditory Brainstem Response (ABR) measurements were repeated prior to noise exposure (day 0 ) and on days 1,7 , and 10 after noise exposure. Intelligent Hearing Systems SmartEP 10(1HS Corp, Miami, FL, USA) version was used for ABR analyses. ABR measurements were recorded by subdermal needle electrodes (Neuroline Subdermal, 12x0.40 $\mathrm{mm}, \mathrm{Ambu} \mathrm{A} / \mathrm{S}, \mathrm{Malaysia})$. The positive electrode was seated on the vertex, the negative electrode was ventrolateral of the test ear and ground electrode was seated on the ventrolateral to the non-test ear. Tone-burst (TB) stimuli were at 4,8 , 12,16 , and $32 \mathrm{kHz}$ with 1 ms rise-fall by a Blackmanwindow envelope in an alternated polarity. Acoustic signals were recorded by band pass filtered $30-3000 \mathrm{~Hz}$, and A/D converted at sampling rate of $25 \mathrm{kHz}$. Analysis time was set 
at $10 \mathrm{~ms}$ and artifact rejection level at $31.00 \mu \mathrm{V}$. The ABR waves were gathered with 1000 stimuli presented at the rate of 37.1/s. Wave II was followed to define the auditory thresholds.

\section{Histological Examinations}

Animals were sacrificed under ether anaesthesia after the final audiological tests. Bullas were extracted and fixed in $10 \%$ formaldehyde. Paraffin blocks were prepared after decalcification with $5 \%$ glacial acetic acid for three days. The organ of Corti and the spiral ganglions were evaluated by light microscopy using hematoxylin-eosin (H\&E) and terminal deoxynucleotidyl transferase mediated dUTP nickend labeling (TUNEL) staining.

\section{Hematoxylin-Eosin Staining}

Bullas were fixed in 10\% buffered formalin (minimum of 48 h) for histological examination and placed in paraffin blocks. Paraffin blocks were placed in rotary microtome (Leica RM 2255, Wetzlar, Germany), and $3 \mu \mathrm{M}$ thick parts were cut. After deparaffinization and hydration, sections were marked with hematoxylin-Eosin (H\&E) (Surgipath, Bretton, Peter Borough, Cambridgeshire, UK). H\&E-stained parts were used to evaluate the general morphology and histological changes of the Corti and spiral ganglion cells on light microscopy.

\section{TUNEL Assay for DNA Fragmentation}

The TUNEL method was used to identify apoptosis. Detection of DNA fragmentation in situ was visualized with the use of the ApopTag Peroxidase in situ Apoptosis Detection Kit (Cat. No. S7100, Merck, Darmstadt, Germany). The kit was used in accordance with the manufacturer's protocol. After fixation and washing, samples were incubated with terminal deoxynucleotidyl transferase (TdT) at $37 \mathrm{C}$ for $1 \mathrm{~h}$. Anti-digoxigenin-peroxidase was used for $30 \mathrm{~min}$ at room temperature and colored with diaminobenzidine. The cells were incubated with this method. The percentage of apoptotic nuclei was calculated as division of the number of counted apoptotic nuclei per total number of nuclei $\times 100 \%$. All counting procedures were performed blindly.

\section{Statistical Analysis}

For statistical analyses SPSS 20.0 (Statistical Package for the Social Sciences, IBM Analytics, NY, USA) statistics software was used. Descriptive statistics were performed for nominal, ordinal and continuous (means and standard deviations) variables. For analyzing the significance of differences between the related and independent groups, non-parametric Kruskal-Wallis test, Mann-Whitney U test and Wilcoxon signed rank test were used. $p<0.05$ was accepted as the level of statistical significance.

\section{Results}

\section{Audiological Findings}

The baseline DPOAE and ABR results were not statistically different between the groups $(p>0.05)$. ABR thresholds and DPOAE results of both group I and II did not show any significant changes in the measurements on days $1^{\text {st }}, 7^{\text {th }}$ and $10^{\text {th }}$ ( $p>0.05$ ). The DPOAE results of groups I and II are given in Table 1.

On the other hand, after noise exposure, ABR thresholds of the noise exposed groups were elevated (Figure 1). Mean TB ABR threshold of group IV was lower than that of group III at all frequencies on the $7^{\text {th }}$ and $10^{\text {th }}$ day measurements, but this difference reached statistical significance $(\mathrm{p}<0.05)$ only on the 10th day measurement at $8 \mathrm{kHz}$ (Figure 1).

Table 1. DPOAE results (SNR) of group I and group II (mean \pm SE)

\begin{tabular}{|c|c|c|c|}
\hline Day & Frequency & Group I (dB SPL) & Group II (dB SPL) \\
\hline \multirow[t]{7}{*}{ Baseline } & $1 \mathrm{kHz}$ & $0.28 \pm 0.2$ & $0.27 \pm 0.1$ \\
\hline & $1.5 \mathrm{kHz}$ & $5.34 \pm 1.3$ & $5.09 \pm 1.4$ \\
\hline & $2 \mathrm{kHz}$ & $12.40 \pm 1.8$ & $11.14 \pm 2.3$ \\
\hline & $3 \mathrm{kHz}$ & $19.60 \pm 2.0$ & $19.58 \pm 1.9$ \\
\hline & $4 \mathrm{kHz}$ & $25.31 \pm 2.0$ & $27.04 \pm 2.2$ \\
\hline & $6 \mathrm{kHz}$ & $39.51 \pm 1.9$ & $40.22 \pm 1.1$ \\
\hline & $8 \mathrm{kHz}$ & $43.97 \pm 1.4$ & $42.54 \pm 1.1$ \\
\hline \multirow[t]{7}{*}{1} & $1 \mathrm{kHz}$ & $0.1 \pm 01$ & $0.87 \pm 0.4$ \\
\hline & $1.5 \mathrm{kHz}$ & $6.5 \pm 1.5$ & $3.88 \pm 1.1$ \\
\hline & $2 \mathrm{kHz}$ & $11.3 \pm 1.5$ & $9.19 \pm 1.5$ \\
\hline & $3 \mathrm{kHz}$ & $18.56 \pm 1.8$ & $19.36 \pm 1.6$ \\
\hline & $4 \mathrm{kHz}$ & $23.9 \pm 1.5$ & $27.84 \pm 2.0$ \\
\hline & $6 \mathrm{kHz}$ & $38.1 \pm 2.05$ & $39.14 \pm 1.1$ \\
\hline & $8 \mathrm{kHz}$ & $40.25 \pm 2.3$ & $38.47 \pm 1.4$ \\
\hline \multirow[t]{7}{*}{7} & $1 \mathrm{kHz}$ & $0.19 \pm 0.1$ & $0 \pm 0$ \\
\hline & $1.5 \mathrm{kHz}$ & $3.80 \pm 1.2$ & $3.63 \pm 1.1$ \\
\hline & $2 \mathrm{kHz}$ & $10.70 \pm 1.5$ & $11.83 \pm 1.9$ \\
\hline & $3 \mathrm{kHz}$ & $24.95 \pm 2.1$ & $24.00 \pm 2.4$ \\
\hline & $4 \mathrm{kHz}$ & $32.95 \pm 1.7$ & $31.9 \pm 2.5$ \\
\hline & $6 \mathrm{kHz}$ & $41.43 \pm 1.3$ & $40.96 \pm 2.9$ \\
\hline & $8 \mathrm{kHz}$ & $42.40 \pm 1.8$ & $43.97 \pm 1.44$ \\
\hline \multirow[t]{7}{*}{10} & $1 \mathrm{kHz}$ & $0.53 \pm 0.4$ & $0.12 \pm 0.1$ \\
\hline & $1.5 \mathrm{kHz}$ & $3.85 \pm 1.1$ & $3.58 \pm 0.9$ \\
\hline & $2 \mathrm{kHz}$ & $9.57 \pm 1.2$ & $9.99 \pm 1.6$ \\
\hline & $3 \mathrm{kHz}$ & $21.59 \pm 1.8$ & $20.72 \pm 1.9$ \\
\hline & $4 \mathrm{kHz}$ & $29.24 \pm 1.8$ & $28.04 \pm 2.3$ \\
\hline & $6 \mathrm{kHz}$ & $39.20 \pm 1.3$ & $40.16 \pm 0.9$ \\
\hline & $8 \mathrm{kHz}$ & $39.83 \pm 1.9$ & $42.44 \pm 1.06$ \\
\hline
\end{tabular}

DPOAE: Distortion Products Otoacoustic Emissions, kHz: Kilohertz, dB SPL: Decibel Sound Pressure Level, SNR: Signal-to-noise ratio, SE: Standard error 
After noise exposure, DPOAE responses had disappeared on the $1^{\text {st }}, 7^{\text {th }}$ and $10^{\text {th }}$ days measurements in both group III and group IV. Thus, we were not able to compare the DPOAE results.

\section{Histological Examination}

\section{Hematoxylin-Eosin Staining}

H\&E-stained sections taken through the organ of Corti and spiral ganglion cells showed normal morphology in both groups I and II. The organization of the Corti organ cells were disrupted in both noise exposed groups. However, the level of disruption was not so much in group IV (Figure 2). The observed disruption might be caused while taking sections by microtome. In both noise exposed groups loss of cells in spiral ganglion neurons were evident, but these pathological changes were less severe in group IV (Figure 3).

\section{TUNEL Assay}

TUNEL Assay showed that noise-induced apoptotic cell death was prominent in the organ of Corti and spiral ganglion cells. Group I and II showed lower TUNEL positive cells than both of groups III and IV. There were more TUNEL positive cells in Group III. The TUNEL results showed that the level of apoptosis was less in the noise exposed KRG group (group IV) (Figure 4). The most significant apoptotic changes were obtained in the spiral ganglion cells (Figure 4). The ratio of apoptotic spiral ganglion cells was decreased in the group IV (33\%) in comparison to group III (92\%) $(\mathrm{p}<0.001)$. The mean percentage of apoptotic cells in the organ of Corti were $67 \%$ and $28 \%$ in group III and group IV, respectively $(\mathrm{p}<0.001$, Figure 5).

\section{Discussion}

The mechanism of NIHL is related to mechanical and metabolic damage. NIHL affects the biochemical systems in the inner ear, leading to necrosis and apoptosis. This change causes permanent hearing loss (21).

KRG extracts have recently been shown to have antiapoptotic and antioxidant effects in various studies $(15,17$,

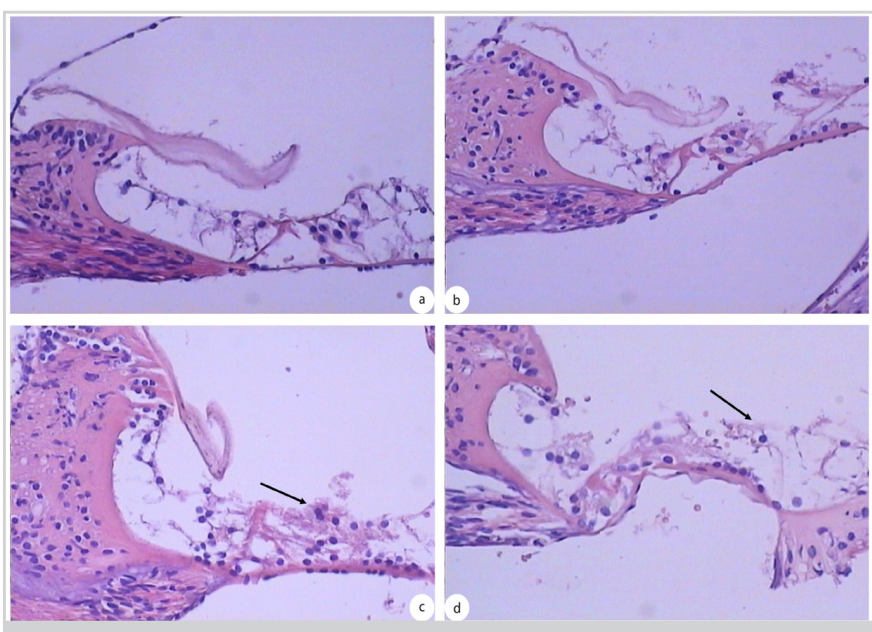

Figure 2. a-d. Hematoxylin-Eosin staining of organ of Corti (a. Group I, b. Group II, c. Group III, d. Group IV). The arrows show that the organization of organ Corti cells are disrupted $(50 \mu \mathrm{m})$
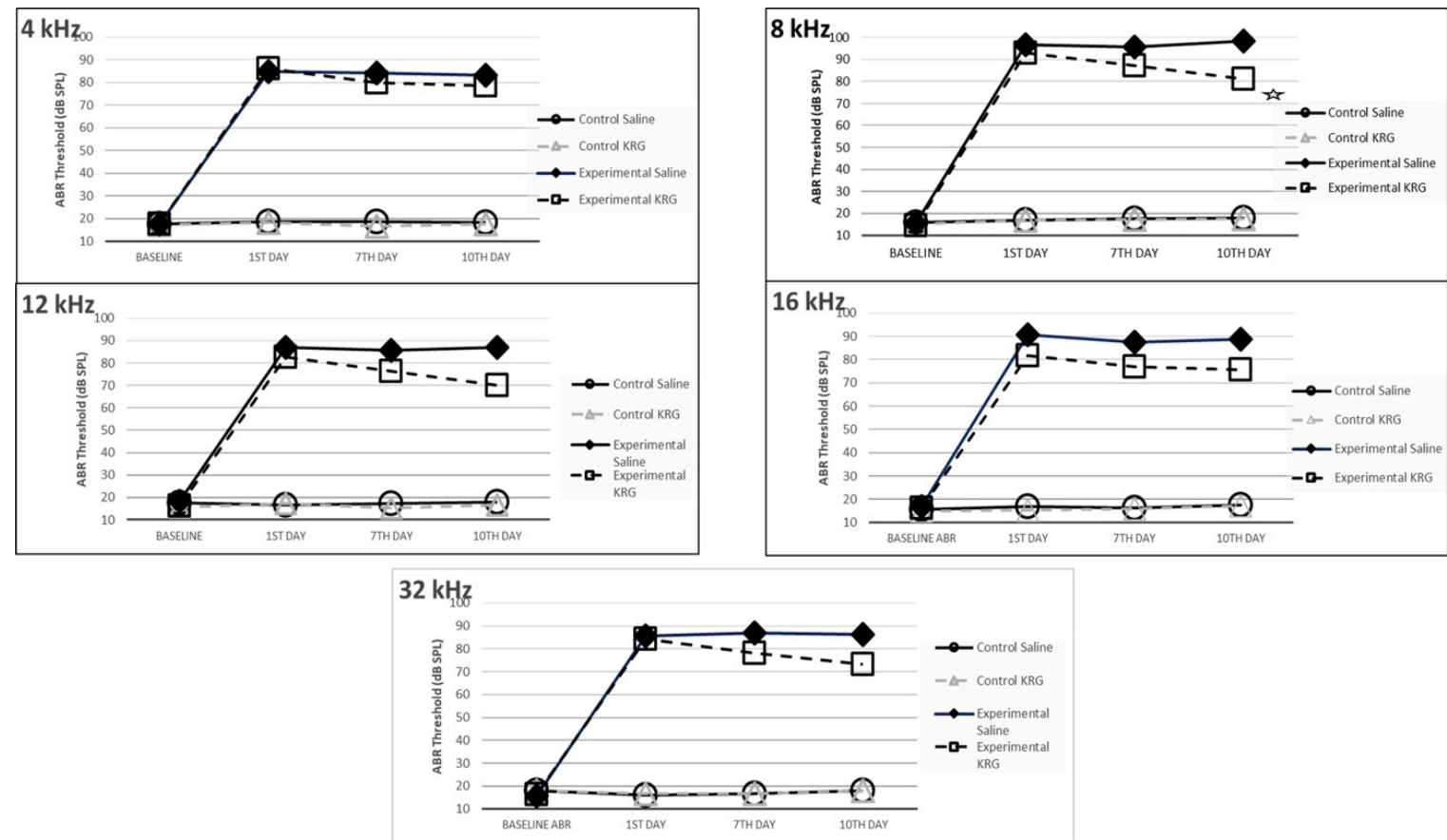

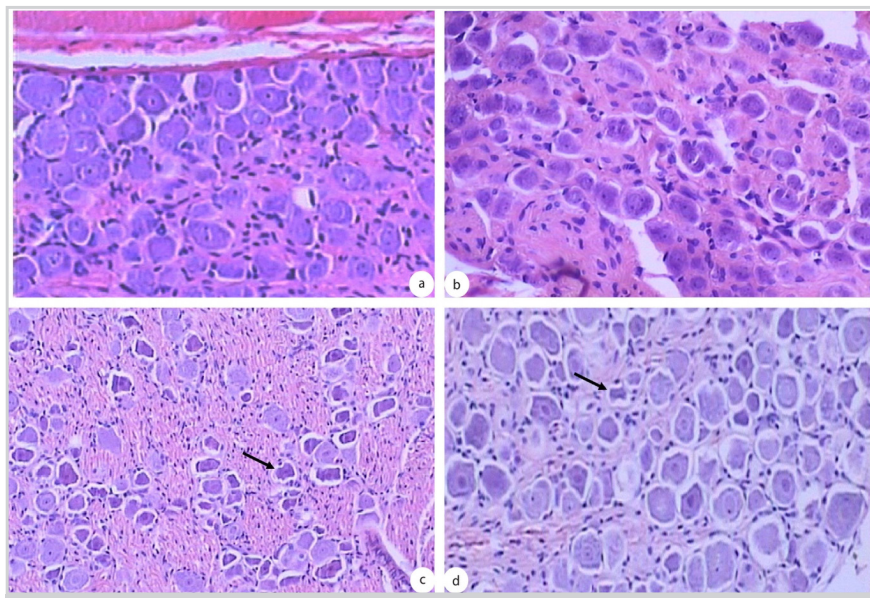

Figure 3. a-d. Hematoxylin-Eosin staining of spiral ganglion cells (a. Group I, b. Group II, c. Group III, d. Group IV). The arrows show the degeneration and picnotic changes in spiral ganglion cells $(200 \mu \mathrm{m})$.
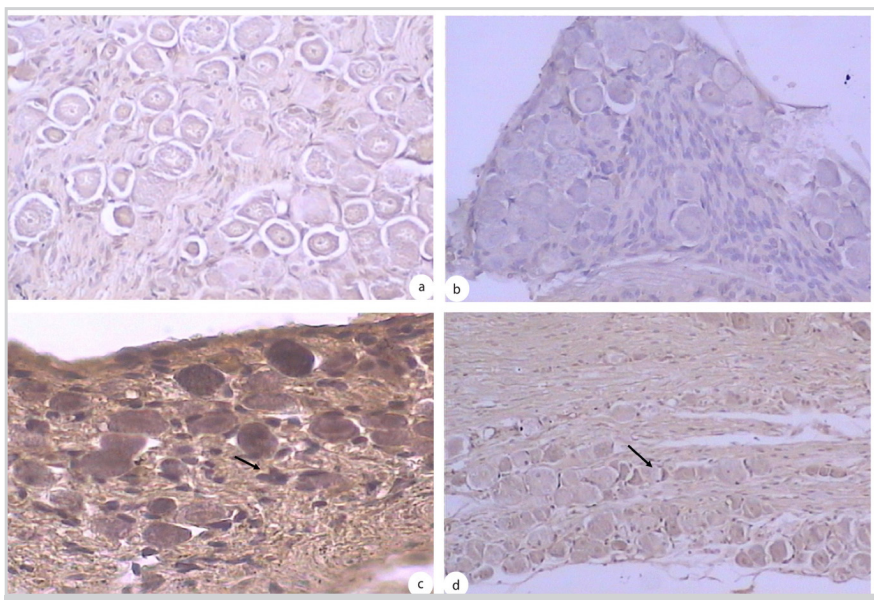

Figure 4. a-d. TUNEL staining of spiral ganglion cells in all groups (a. Group I, b. Group II, c. Group III, d. Group IV). Arrows shows TUNEL positive (apoptotic) cells $(400 \mu \mathrm{m})$

TUNEL: Terminal deoxynucleotidyl transferase mediated dUTP nick-end labeling

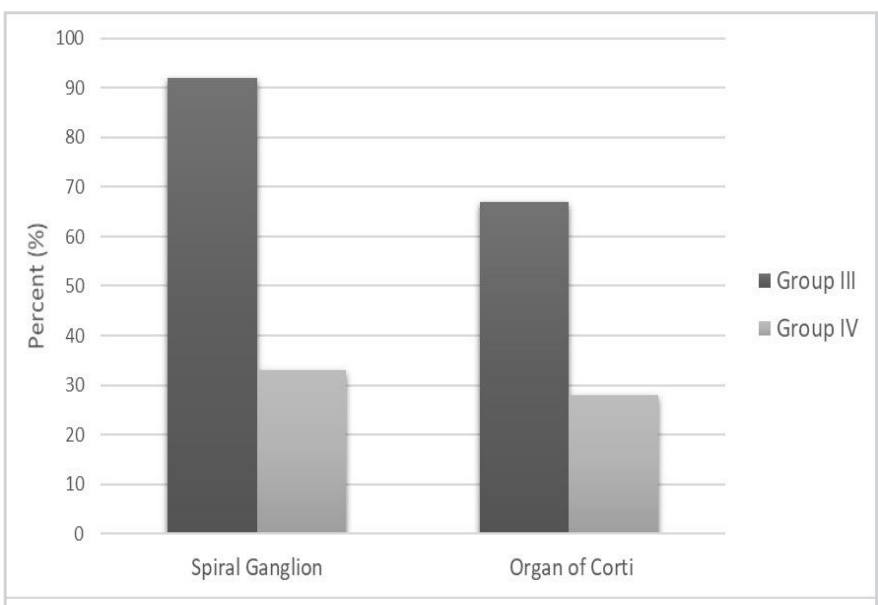

Figure 5. Apoptotic cell ratio in organ of Corti and spiral ganglion
19, 22, 23). Recently, some studies showed that KRG and ginsenosides (found in ginseng) have otoprotective properties against age-related hearing loss, gentamicin, 3-nitropropionic acid, cisplatin ototoxicity, and noise-induced hearing loss (15, $16,18-21)$.

In the literature there were only two studies about the effect of KRG in NIHL. Kang and Chung (21), administered 200 $\mathrm{mg} / \mathrm{kg}$ KRG orally for three days to mice, starting from one hour after the $110 \mathrm{~dB}$ SPL white noise (three hours). After noise exposure, the click ABR results of the KRG group were significantly better than the control saline group. On the $7^{\text {th }}$ day, all groups returned to their basal hearing values and it was considered as a temporary threshold shift. The authors indicated that KRG had rapid recovery effect for temporary threshold shifts, and long-term results for permanent hearing loss might be better (21).

In our study, we investigated the effect of KRG on permanent NIHL and the wide hearing frequency range of the rats allowed us to evaluate the most affected high frequency region in NIHL. We used high frequency TB stimuli in $\mathrm{ABR}$. To our knowledge, this is the first research using high frequency TB ABR on the effect of KRG for NIHL.

In their research, Hong et al. (24) tested various doses of 50 $\mathrm{mg} / \mathrm{kg}$ and $100 \mathrm{mg} / \mathrm{kg}$ ginsenosides compounds, KRG and ginseng compounds 24 hours after the $120 \mathrm{~dB}$ SPL, $4 \mathrm{kHz}$, pure tone noise ( 2 hours) for seven days. The effects of KRG and ginsenosides compounds were evaluated by TEOAE, $A B R$ and middle latency responses (MLR) after the $1^{\text {st }}, 4^{\text {th }}$ and $7^{\text {th }}$ days. SNR was assessed in the TEOAE test, which was used to evaluate outer hair cell function. Significantly, better SNR responses were obtained in the group of ginsenoside compounds. The KRG group showed better ABR thresholds at 4,6 , and $8 \mathrm{kHz}$ than the control group. It has been stated that KRG $(100 \mathrm{mg} / \mathrm{kg})$ and ginsenoside compounds have a protective effect for NIHL. In the study of Hong et al. (24) the ginseng compounds were administered for seven days and in our study the powder form of ginseng root was given for 10 days.

Choung et al. (15) reported the protective effects of KRG against gentamicin-induced ototoxicity, and Kang and Chung (21) also stated that, for NIHL, ginseng had reactive oxygen species repellent and apoptotic potency properties and might have a protective role in the ear. Kang and Chung (21) did not observe 8-oxoguanine as a ROS indicator after noise exposure. In our study, TUNEL (+) cells were less visible in group IV than in group III, especially in the spiral ganglion cells. This may be indicative of the protective effect of KRG in NIHL, as stated by referred studies $(15,21)$.

Fujita et al. (25) investigated the protective effect of the intravenous infusion of ginseng compound $\mathrm{gRb} 1$ on spiral 
ganglion cells in the cochlear ischemia model of gerbils. In their study, with the application of $\mathrm{gRb} 1$ the ratio of TUNEL positive cells decreased from $25 \%$ to $5 \%$ and the authors concluded that $\mathrm{gRb} 1$ had otoprotective properties in cochlear ischemia model in gerbils (25).

In our study, antioxidant application was started within 1 hour after noise exposure since in daily life it is not always predictable when traumatic situations (such as in industry, armed forces, entertainment places, or unexpected bursts) will occur. We found a partial protective effect of KRG against NIHL which was prominent on $8 \mathrm{kHz}$.

According to some studies concerning NIHL, presbycusis, and ototoxicity, pathological changes firstly occur in the hair cells and the damage in the spiral ganglions neurons occurs after that $(25,26)$.

Our histopathological results showed that in Group IV, application of KRG had a significant protective effect on both hair cells and spiral ganglion neurons. Apoptotic cell ratio in hair cells and spiral ganglion neurons were 28\% and $33 \%$ in Group IV in contrast to the higher apoptosis ratio in group III ( $67 \%$ and $92 \%$, respectively). According to our histopathologic evaluations, KRG showed prominent protection in terms by preventing apoptosis. Although we saw some improvements on hearing levels with the KRG treatment, we think that this protection was not completely reflected in our audiological results. We think that other possible cellular death mechanisms like necrosis may be a possible explanation for these results. The primary limitation of this study is the fact that our DPOAE device was not able to measure higher frequencies above $8 \mathrm{kHz}$.

\section{Conclusion}

Our results have shown that there is a partial protective effect of KRG on NIHL. This protection was more prominent on $8 \mathrm{kHz}$ and histopathologically more evident in both hair cells and spiral ganglion neurons. There is, however, need for further research to demonstrate the mechanisms of this protective effect, and to determine the optimal dose and the optimal timing for this protection on permanent noiseinduced hearing loss models (impact sound, burst, repetitive, wavy).

\section{Acknowledgement}

KRGs were supplied from the Korean Red Ginseng Corporation (Taejon, Korea) with kind supports of Prof. Chong Sun Kim from Seoul National University. We would like to thank Prof. Nur Olgun who was abundantly helpful and offered invaluable assistance, support and guidance.
Informed Consent: Animal experiment study.

Peer-review: Externally peer-reviewed.

\section{Authorship Contributions}

Conception: S.M.D., Y.O., S.A., H.E.E., S.G., Z.A., B.M., E.K., E.D., O.Y., G.K., Design: S.M.D., Y.O., S.A., H.E.E., S.G., Z.A., B.M., E.K., G.K., Data Collection and/or Processing: S.M.D., Y.O., S.A., H.E.E., S.G., Z.A., B.M., E.K., E.D., O.Y., G.K., Analysis and/or Interpretation: S.M.D., S.A., S.G., E.D., G.K., Literature Review: S.M.D., H.E.E., S.G., B.M., E.K., E.D., Writing: S.M.D., Y.O., S.A., H.E.E., S.G., Z.A., B.M., E.K., E.D., O.Y., G.K.

Ethics Committee Approval: Ethics committee approval was received for this study from the Ethics Committee of Animal Care and Use of the Dokuz Eylül University (Protocol number: 46/2014).

Conflict of Interest: No potential conflict of interest relevant to this article was reported.

Financial Disclosure: The authors declared that this study has received no financial support.

\section{Main Points}

- Noise exposure can damage hair cells, spiral ganglion neurons and result in hearing loss.

- Korean Red Ginseng attenuates hair cell and spiral ganglion neurons loss induced by noise exposure.

- Korean Red Ginseng may be a protective agent for noiseinduced hearing loss.

\section{References}

1. Kang TH, Hong BN, Park C, Kim SY, Park R. Effect of baicalein from Scutellaria baicalensis on prevention of noise-induced hearing loss. Neurosci Lett 2010; 469: 298-302. [Crossref]

2. Sullivan JM, Cohen MA, Pandit SR, Sahota RS, Borecki AA, Oleskevich S. Effect of epithelial stem cell transplantation on noise-induced hearing loss in adult mice. Neurobiol Dis 2011; 41: 552-9. [Crossref]

3. Choi CH, Du X, Floyd RA, Kopke RD. Therapeutic effects of orally administrated antioxidant drugs on acute noise-induced hearing loss. Free Radic Res 2014; 48: 264-72. [Crossref]

4. Sareen A, Singh V. Noise induced hearing loss: a review. Online J Otolaryngol 2014; 4: 1-10. [Crossref]

5. Yamasoba T, Pourbakht A, Sakamoto T, Suzuki M. Ebselen prevents noise-induced excitotoxicity and temporary threshold shift. Neurosci Lett 2005; 380: 234-8. [Crossref]

6. Kopke RD, Coleman JK, Liu J, Campbell KC, Riffenburgh RH. Candidate's thesis: enhancing intrinsic cochlear stress defences to 
reduce noise-induced hearing loss. Laryngoscope 2002; 112: 151532. [Crossref]

7. Le Prell CG, Yamashita D, Shujiro B. Minami SB, Yamasoba T, Miller JM. Mechanisms of noise-induced hearing loss indicate multiple methods of prevention. Hear Res 2007; 226: 22-43. [Crossref]

8. Ohinata Y, Yamasoba T, Schacht J, Miller JM. Glutathione limits noise-induced hearing loss. Hear Res 2000; 146: 28-34. [Crossref]

9. Kurabi A, Keithley EM, Housley GD, Ryan AF, Wong AC. Cellular mechanisms of noise-induced hearing loss. Hear Res 2017; 349: 129-37. [Crossref]

10. Noreña AJ, Eggermont JJ. Enriched acoustic environment after noise trauma reduces hearing loss and prevents cortical map reorganization. J Neurosci 2005; 25: 699-705. [Crossref]

11. Tornabene SV, Sato K, Pham L, Billings P, Keithley EM. Immune cell recruitment following acoustic trauma. Hear Res 2006; 222: 115-24. [Crossref]

12. Han MA, Back SA, Kim HL, Park SY, Yeo SW, Park SN. Therapeutic effect of dexamethasone for noise-induced hearing loss: systemic versus intratympanic injection in mice. Otol Neurotol 2015; 36: 755-62. [Crossref]

13. Alvarado JC, Fuentes-Santamaría V, Juiz JM. Antioxidants and vasodilators for the treatment of noise-induced hearing loss: are they really effective? Front Cell Neurosci 2020; 14: 226. [Crossref]

14. Yu SE, Mwesige B, Yi YS, Yoo BC. Ginsenosides: the need to move forward from bench to clinical trials. J Ginseng Res 2019; 43: 361-7. [Crossref]

15. Choung YH, Kim SW, Tian C, Min JY, Lee HK, Park SN, et al. Korean red ginseng prevents gentamicin-induced hearing loss in rats. Laryngoscope 2011; 121: 1294-302. [Crossref]

16. Tian C, Kim YH, Kim YC, Park KT, Kim SW, Kim YJ, et al. Korean red ginseng ameliorates acute 3-nitropropionic acidinduced cochlear damage in mice. Neurotoxicology 2013; 34: 4250. [Crossref]
17. Im GJ, Chang JW, Choi J, Chae SW, Ko EJ, Jung HH. Protective effect of Korean red ginseng extract on cisplatin ototoxicity in HEIOC1 auditory cells. Phytother Res 2010; 24: 614-21. [Crossref]

18. Tian C, Kim YJ, Lim HJ, Kim YS, Park HY, Choung YH. Red ginseng delays age-related hearing and vestibular dysfunction in C57BL/6 mice. Exp Gerontol 2014; 57: 224-32. [Crossref]

19. Tian CJ, Kim SW, Kim YJ, Lim HJ, Park R, So HS, et al. Red ginseng protects against gentamicin-induced balance dysfunction and hearing loss in rats through antiapoptotic functions of ginsenoside Rb1. Food Chem Toxicol 2013; 60: 369-76. [Crossref]

20. Olgun Y, Kırkım G, Altun Z, Aktaş S, Kolatan E, Kiray M, et al. Protective effect of Korean red ginseng on cisplatin ototoxicity: Is it effective enough? J Int Adv Otol 2016; 12: 177-83. [Crossref]

21. Kang WS, Chung JW. Ingestion of Korean red ginseng after noise exposure can potentiate rapid recovery of hearing in mice. J. Ginseng Res 2010; 34: 336-41. [Crossref]

22. Choi J, Kim TH, Choi TY, Lee MS. Ginseng for health care: a systematic review of randomized controlled trials in Korean literature. PLoS One 2013; 8, e59978. [Crossref]

23. Lee J, Kim MJ, Han GC. Effect of Korean red ginseng on early vestibular function restoration after unilateral labyrinthectomy. Res Vestib Sci 2020; 19: 79-88. [Crossref]

24. Hong BN, Kim SY, YiTH, Kang TH. Post-exposure treatment with ginsenoside compound $\mathrm{K}$ ameliorates auditory functional injury associated with noise-induced hearing loss in mice. Neurosci Lett 2011; 487: 217-22. [Crossref]

25. Fujita K, Hakuba N, Hata R, Morizane I, Yoshida T, Shudo $\mathrm{M}$, et al. Ginsenoside Rb1 protects against damage to the spiral ganglion cells after cochlear ischemia. Neurosci Lett 2007; 415: 113-7. [Crossref]

26. Ryals BM, Ten Eyck B, Westbrook EW. Ganglion cell loss continues during hair cell regeneration. Hear Res 1989; 43: 81-90. [Crossref] 